\title{
Efficiency of Portable Electronic Vulcanizer
}

\author{
Eduardo Zeta Ramis \\ Technology Department, University of Eastern Philippines, Catarman, Philippines \\ Email: edz ramis@yahoo.com \\ Received 22 January 2015; accepted 9 February 2015; published 12 February 2015 \\ Copyright (c) 2015 by author and Scientific Research Publishing Inc. \\ This work is licensed under the Creative Commons Attribution International License (CC BY). \\ http://creativecommons.org/licenses/by/4.0/ \\ (c) (i) Open Access
}

\section{Abstract}

This research was aimed at finding out the efficiency of the portable electronic vulcanizer. The old vulcanizing equipment was upgraded to save time, investment, manpower and to eliminate the problem of gas emission in vulcanization. The study also determined the accurate temperature setting and duration of vulcanizing process using electronic vulcanizer which eliminated the problem of gas emission produced by the conventional (gas fired) vulcanizer of about $2.772 \mathrm{~kg}$ of carbon dioxide for 1 liter of diesel fuel and/or $2.331 \mathrm{~kg}$ of carbon dioxide for 1 liter of petrol into the atmosphere. In constructing this vulcanizer, a letter $\mathrm{G}$ body configuration made of GI pipe with $31.5 \mathrm{~cm}$ long lag bolt with some electronic parts were installed, like the analog temperature gauge, digital timer, relay, LED, buzzer, switch, and heating element. Specifically, the product is divided into three components: base or body, control panel board and the heating unit. The effectiveness level of the equipment was tested utilizing five different temperatures at a constant and variable time. For Class A gum, the best temperature which bonded the gum exactly to the rubber tire was $60^{\circ} \mathrm{C}$ in 1 minute while Class $B$ gum was bonded at $60^{\circ} \mathrm{C}$ in 2 minutes. The rate of energy consumed by the electronic vulcanizer for Class A gum was Php 0.0757 with an efficiency of $85.22 \%$ and for Class B gum was Php 0.15 with an efficiency of $85.22 \%$ and for conventional vulcanizer for Class $A$ gum was Php 1.08 with an efficiency of $43.38 \%$ and for Class B gum was Php 1.52, with an efficiency of $78.08 \%$. The study revealed that more tires could be vulcanized in a short period of time, therefore providing greater income over time. It is also environment-friendly since it does not emit carbon dioxide as compared to the conventional vulcanizing.

\section{Keywords}

Electric Vulcanizer, Portable Electronic Vulcanizer, Environment-Friendly Machine

\section{Introduction}

This research is about the upgrading of the vulcanizing equipment for automobile, motorcycle, bicycle and any 
tire tubes. The gadget is electronically operated and environment-friendly.

The upgraded vulcanizing equipment has additional features such as buzzer, timer and temperature gauge which can greatly increase its efficiency and accuracy.

This experimental research was conceived to help reduce global warming, and to encourage investors in this small scale business industry.

This study aimed at finding out the accurate temperature and duration of vulcanizing process using the electronic vulcanizer which eliminated the problem of gas emission (carbon dioxide) produced by the conventional (gas fired) vulcanizer of about $2.772 \mathrm{~kg}$ of carbon dioxide for 1 liter of diesel fuel and/or $2.331 \mathrm{~kg}$ of carbon dioxide for 1 liter of petrol into the atmosphere [1].

\section{Technical Description}

\subsection{Objectives}

The portable electronic vulcanizer was tested to find out its efficiency and convenience, which is beneficial to the community, the environment and industry.

Specifically, this study was conducted to:

1) identify the design of a portable electronic vulcanizer;

2) determine its material components;

3) determine the appropriateness of the heating element used in this electronic vulcanizer;

4) determine the desirable temperature to exactly bond the Class A and B vulcanizing gum to the rubber tire in one and two minutes, respectively; and

5) find out the efficiency and cost of the portable electronic vulcanizer.

\subsection{Rationale}

The underlying principle of this study is to determine the efficiency of the portable electronic vulcanizer and to eliminate the problem of gas emission in vulcanizing shops.

\subsection{State of the Art}

The upgrading of the conventional vulcanizer (gas emitting apparatus) requires the researcher to introduce a new idea in this field of technology. The experimental set-up was made of different temperatures at a constant time in vulcanization. Five trials were conducted to find the perfect temperature on which the gum will bond to the rubber perfectly at 1 minute for Class A vulcanizing gum and 2 minutes for Class B vulcanizing gum.

\subsection{Analysis of the Problem}

The electric vulcanizer and the conventional vulcanizer (gas emitting apparatus) have a common problem. The electric vulcanizer, if not undertaken properly during the vulcanization process, can damage the rubber tire. In the conventional vulcanizer, if the gas is not properly measured or controlled, burning of the rubber tire will occur. To solve the aforementioned problem as well as on gas emission, this innovative technology (electronic operated vulcanizer) was studied to cut down cost on investment and manpower in the vulcanizing industry.

\subsection{Flowchart of the Study}

Figure 1 shows the flow chart of the study. The input includes the heating elements, temperature and timer meter, LED monitors, buzzer, steel plate and power switch in making the product. The process includes the steps in making the product and data gathering. The output is the portable electronic vulcanizing (PEV) equipment.

\section{Review of Literature}

The work environment refers to the aggregate of surrounding things and conditions that affect the quality of work life and the individual itself being an employee or an entrepreneur.

Former President Fidel V. Ramos [2] stressed that the living condition of the people in every sector of society must be improved by initiating family investment or group. He wanted then to make the Philippines a New 


\begin{tabular}{|c|c|c|}
\hline \multicolumn{1}{|c|}{ Input } & Process & Output \\
\hline Heating Elements & Welding & Portable \\
Temperature meter & Boring & Electronic \\
Timer meter & Connection of wires \\
Relay & Soldering of terminals & Vulcanizing \\
LED monitors & Riveting \\
Buzzer & Bolting \\
Steel plate & Panel Board \\
Power switch & Testing of products & Equipment \\
& Data gathering & \\
\hline
\end{tabular}

Figure 1. Flow chart of the study.

Industrialize Country (NIC) in Asia and the Pacific, by 2000 and beyond. Thus, Executive Order No. 318, s. 1991, was passed to reinforce functional program in the implementation toward industrial reform and development.

Technical Education Skills Development Authority (TESDA), reported that the government's quest to realign technical education program be of paramount importance. On the other hand, the Presidential Commission on Educational Development (EDCOM), on their survey resulted in recommending to conduct feasibility studies and projected modern educational design to revitalize the nation's changing demand of the youth for effective manpower development. Mismatch problem of the education sector and industry is of vital issue as regards the graduation rates of colleges and universities which most of them cannot find job, because of lack of skills needed by the industry. Hence, technical graduates have wider range of employment compared to those graduates of white collar profession [3].

Vulcanization is the chemical process by which the physical properties of natural or synthetic rubber are improved; finished rubber has higher strength and resistance to swelling and abrasion, and elastic over a greater range of temperature. In its simplest form, heating rubber with sulfur brings about vulcanization.

In modern practice, temperature of about $140^{\circ} \mathrm{C}-180^{\circ} \mathrm{C}$ is deployed, and in addition to sulfur and accelerations, carbon black oxide is usually added, not merely as an extender, but improves further the qualities of the rubber. Vulcanizing gum, which is a classified as "ready to heat" rubber, is now utilized to repair worn out interior/exterior rubber tires with the help of vulcanizing equipment. Certain problems such as inaccuracy of the product are evident in third-world countries, as the first-worlds never used some [4].

\subsection{The Discovery of Vulcanization}

Goodyear thought that rubber might be improved by processing it with other substances. As Goodyear was displaying a mixture of rubber and sulfur, the piece slipped from his hand into the fire. When he looked it out he found to his amazement that the mass has charred without melting. Goodyear named this process of combining rubber with sulfur by heat "vulcanization". Later he discovered that the addition of lime, magnesia, and lead compounds speeded up vulcanization process. Elastic substance obtained from the exudations of certain tropical plants (natural rubber) or derived from petroleum and alcohol (synthetic rubber) [5].

In the process of vulcanization, sulfur atoms form cross-links between the chain molecules of rubber, tying them firmly together. The vulcanization process causes some striking changes in the property of rubber. The rubber remains elastic at both low and high temperatures. Its strength is increased and it can be stretched to greater lengths than before. It will no longer dissolve in gasoline or benzene, though it will swell up if it is soaked in them.

Newly discovered rubber class such as vulcanizing gum is now utilized in repairing worn-out rubbers such as an automobile tire. Vulcanizing gum is classified according to its texture, bonding temperature and the content of accelerators. The three classes of the gum were as follows [5]:

$>$ Class A-usually bonds on the rubber $30^{\circ} \mathrm{C}-70^{\circ} \mathrm{C}$ and is smooth; 
$>$ Class $\mathrm{B}$-usually bonds on the rubber $35^{\circ} \mathrm{C}-80^{\circ} \mathrm{C}$ and is moderately rough;

Class C-usually bonds on the rubber $45^{\circ} \mathrm{C}-90^{\circ} \mathrm{C}$ and is very rough.

\subsection{Related Studies}

A tire vulcanizer which can make a bladder supply pressurized fluid at a tire vulcanization position and a shaping position, disconnects the channel during movement of a lower container, and can move the bladder while keeping the internal pressure of the bladder. Under a state where the lower container (2) moved to the shaping position $\mathrm{N}$, a downstream side moving tube (5) is connected to a second fixed tube (62) through a second joint (72), and pressurized fluid is supplied from a fluid supply unit (42) to the bladder (3) so that a green tire can be shaped. Under a state where the lower container moved to the tire vulcanization position $\mathrm{M}$, the downstream side moving tube (5) is connected to a first fixed tube (61) [6].

A tire vulcanizer is equipped with an inner circumferential wall which surrounds a center post, an outer circumferential wall which surrounds the aforementioned inner circumferential wall, a partitioning wall which radially divides the space between the aforementioned inner circumferential wall and the aforementioned outer circumferential wall into an inner space toward the aforementioned inner circumferential wall and connected to a bladder, and an outer space toward the aforementioned outer circumferential wall and connected to the aforementioned bladder, and a circulation means which cyclically supplies and discharges a heated liquid into and out of the aforementioned bladder via the aforementioned inner space and the aforementioned outer [7].

Ramis [8] cited in his dissertation that technological development begins with basic research, when a scientist discovers some new phenomenon or advances new theory. Other researchers examined the breakthrough for its potential utility. If further developed, it leads to a prototype and engineering refinement makes commercial exploitation practical. Then, the technology is finally put to, use may be widely adopted.

Technological change takes place in many directions at once, that is, it is multi-final. Bar codes, for example, are used to track items not only in grocery stores but also in warehouses, assembly lines, shipping docks, libraries, even in the Department of Defense. Technological changes are also nonlinear; Developments take irregularly. There are many dead ends, and each highly visible advance may depend on a host of small developments (including failures) [8].

Actually, there are now vulcanizing equipment in the market plus the Internet ads, there are roughly 1000 vulcanizers that are electric/electronic operated but they don't have timer nor temperature control and none of them beat my design. Commercial vulcanizer (electric \& manual) if not properly used, the vulcanizing gum may be burned same with the tire; this holds true with manually operated machine. Compared to the manually operated vulcanizing equipment, this electronic operated vulcanizer saves time, labor, money and manpower in the vulcanizing shop operation.

\section{Methodology}

This section discusses the processes that were done during the experimentation.

\subsection{Research Design}

The study utilized experimental research method which included the new design, selection and identification of materials, assemblage fabrication, and testing process:

1) New design. The design of the vulcanizing equipment was based on its portability and light weight of 6.30 kilograms, and environment-friendly machine. Its body configuration is a letter $G$ in appearance that is made of GI pipe of schedule 40 and $3 \mathrm{~cm}$ in diameter; the base was made of $0.3 \mathrm{~cm}$ flat bar that serves as foundation of the equipment; a flat type 300 watts heating element and a box type panel board.

2) Selection and identification of materials. Selection and identification of materials were seriously considered in this study. The timer that controls the duration of the vulcanizing process; temperature gauge that controls the temperature in the process; power switch that is used for cutting the power supply to the machine; LED as light monitoring device and the buzzer that sounds when the vulcanizing process is completed; a stainless circular handle with $315 \mathrm{~mm}$ by $12 \mathrm{~mm}$ lag bolt, used for pressing the heating element and the rubber tire, and a flat type 300 watts heating element was connected to the circuit which is enclosed by a panel board made of galvalum sheet to complete the portable electronic vulcanizer. 
3) Fabrication. Based on the plans and design, the body was molded in a pipe bender to form a letter G configuration, the flat bar was cut to its desired length then welded to form the base and welded it again to the body of the vulcanizer. Fabrication of the panel board was undertaken to house the circuit board of this machine.

4) Testing process. Testing of the machine was undertaken to determine the workability of the machine.

Figure 2 shows the schematic diagram of the electronic vulcanizing equipment.

Figure 3 shows the full view of the portable electronic vulcanizer (PEV).

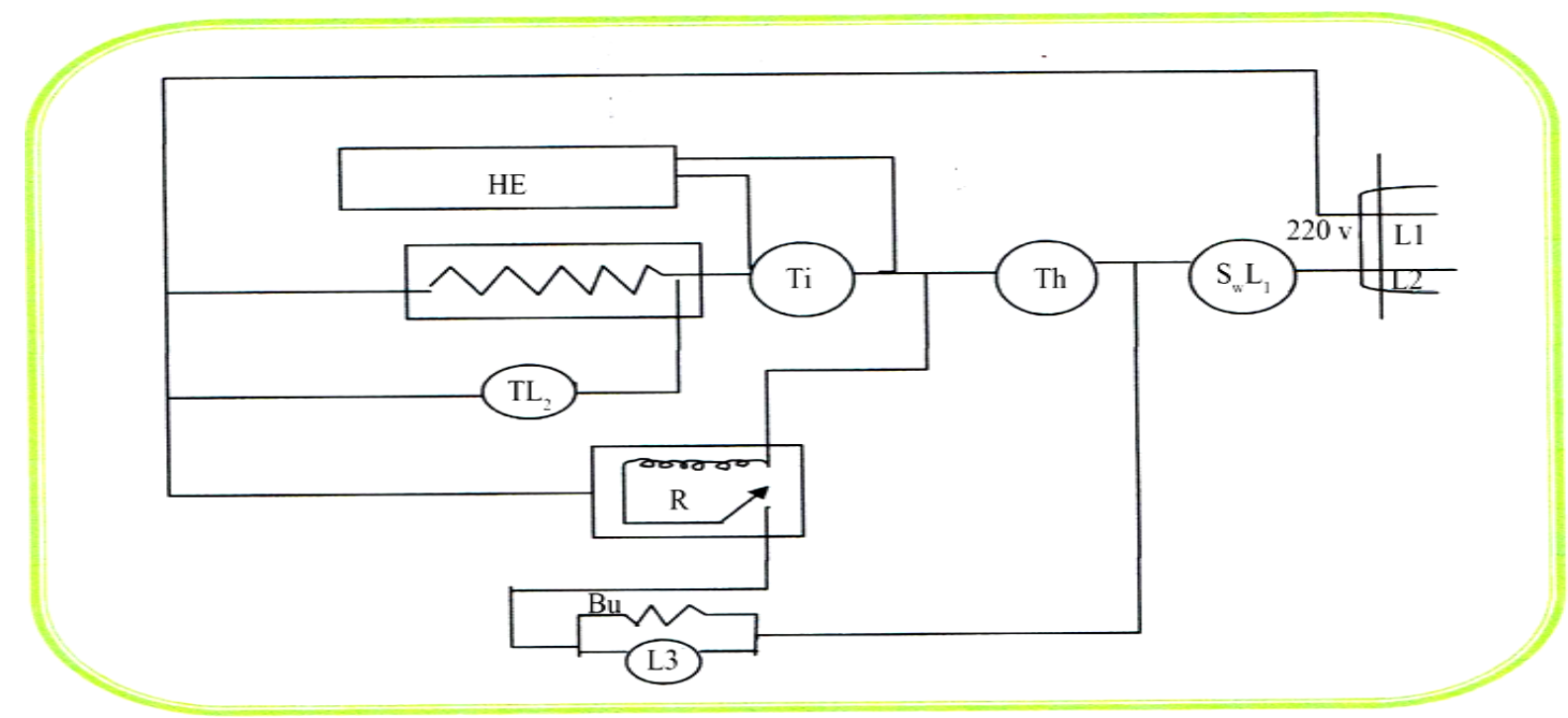

Figure 2. Schematic diagram of the vulcanizing equipment. Legend: $\mathrm{L}_{1} / \mathrm{L}_{2}=$ power supply 220 volts. Ti $=$ digital timer. $T L_{2}$ $=$ LED monitor for heating element. $\mathrm{R}=$ relay. $\mathrm{Bu}=$ buzzer. $\mathrm{S}_{\mathrm{w}} \mathrm{L}_{1}=$ power switch/LED monitor. Th = analog temperature gauge (thermostat). $\mathrm{L}_{3}=\mathrm{LED}$ monitor for relay. $\mathrm{HE}=$ heating element. $\mathrm{Wm}=$ resistor.

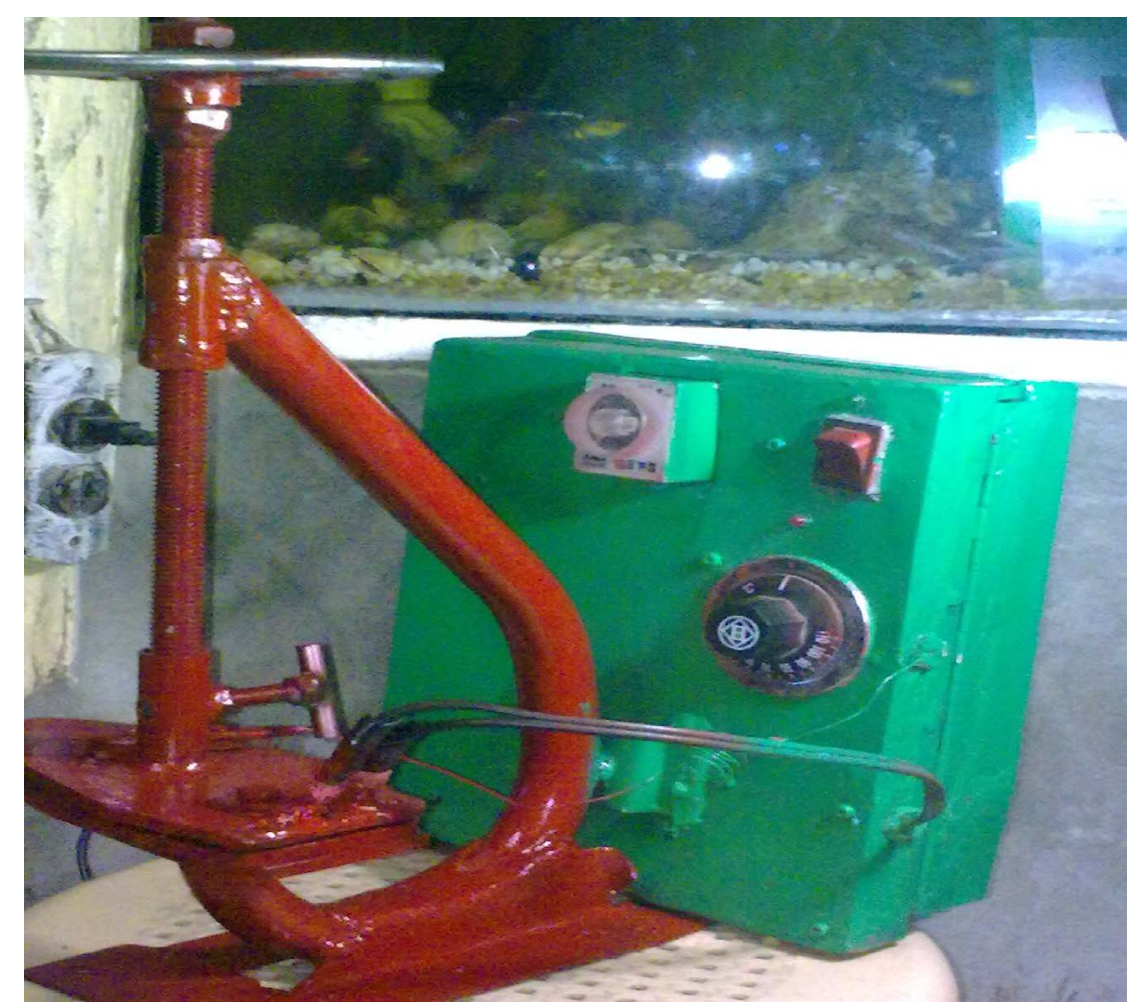

Figure 3. The portable electronic vulcanizer (PEV). 


\subsection{Materials}

The materials and methods used in the construction and experimentation of this study were:

- a heating element, a 300 watts heating device that heats the vulcanizing gum and rubber or interior tire for vulcanizing process;

- an analogue temperature gauge used to set specific degrees in centigrade for the duration of the vulcanization process;

- a digital timer device used to set a specified time in seconds/minutes/hours for the burning operation of the vulcanizing equipment;

- a printed circuit board (PCB) on which all of the electronic parts were installed;

- a light emitting diode (LED) that serves as light monitoring device;

- boring tools used for drilling holes in the PCB for placement of the electronic parts;

- a relay to conduct power to the timer, temperature gauges once the vulcanization process takes place;

- a buzzer that sounds when the heating activity is finished;

- bolts and nut used to tighten some electronic parts to the PCB and as holder of the PCB circuit;

- a circuit is made in a PCB so that current will flow;

- a hacksaw that is used for cutting metals as parts of the machine;

- a welding machine is used to join metals for assembling the vulcanizer;

- aluminum sheeting is used as shield or protector of the rubber tire during vulcanizing process;

- a control panel houses the component parts of the electronic vulcanizer;

- power switches for power connection to the circuit or vulcanization process;

- the main source provides a prescribed current to any circuit connected to it; and

- the body of vulcanizer that is the holder of all the component parts used in this vulcanizer.

The connection of wirings was assessed by the researcher with the assistance of an electronic expert to ensure workability of the equipment. For mass production, this machine costs Php 5700.00 (US \$101.79) only.

To determine the efficiency of the product in vulcanization, the researcher used some worn-out automobile tires to be vulcanized. Several tires were vulcanized at different temperatures and time with the temperature interval of $10^{\circ} \mathrm{C}$ ranging from $30^{\circ} \mathrm{C}$ to $60^{\circ} \mathrm{C}$ and a constant time of 1 minute. The results were then recorded and determined what temperature and time the vulcanizing gum exactly bonded to the tire.

\section{Results and Discussion}

The following are the data collected based on the actual testing, observation and experimentation of the researcher.

The design of the portable electronic vulcanizer machine is made of steel materials. Its body is like big letter $\mathrm{G}$ configuration and on the bottom part of the machine is the heating element were the processes of vulcanization takes place.

The design and fabrication of the portable electronic vulcanizer are illustrated below:

$>$ The galvanized iron (GI) Pipe with the dimension of $600 \mathrm{~cm}$ and gauge 20 and $3 \mathrm{~cm}$ in diameter was formed into big letter G;

$>$ The finished product, the portable electronic vulcanizer stands perpendicular to the ground with the height of $43 \mathrm{~cm}$;

In the back side of the vulcanizer is the housing of the panel board where the control gadget is located;

$>$ The PCB is located under the housing of the panel board where the switch, timer, digital temperature gauge, LED monitors, buzzer and relay are interconnected to form a circuit;

$>$ The circuit is connected to the heating element of the electronic vulcanizer;

$>$ Then a power cord is connected to the circuit for power supply connection.

Data on Table 1 shows that the electronic vulcanizer had the best temperature in which the gum was bonded exactly to the rubber tire. It was $60^{\circ} \mathrm{C}$ in 1 minute for Class A gum with a power consumption of $0.005 \mathrm{~kW} \cdot \mathrm{h}$ valued at Php 0.0757 and an efficiency of $85.22 \%$, while the Class B gum bonded at 2 minutes at $60^{\circ} \mathrm{C}$, with power consumption of $0.10 \mathrm{~kW} \cdot \mathrm{h}$ valued at Php 0.15 and an efficiency of $85.22 \%$.

For the conventional vulcanizer, the best temperature in which the gum was bonded exactly to the rubber tire was $60^{\circ} \mathrm{C}$ in 5 minutes for Class A gum, with fuel consumption of $20 \mathrm{ml}$ valued at Php 1.08 and an efficiency of $43.38 \%$, while the Class $\mathrm{B}$ gum was bonded at 10 minutes at $60^{\circ} \mathrm{C}$, fuel consumption of $30 \mathrm{ml}$ valued at Php 
Table 1. Efficiency and rate of energy consumption of electronic/conventional vulcanizing using Class A and Class B vulcanizing gum.

\begin{tabular}{|c|c|c|c|c|c|c|c|c|c|c|c|c|c|}
\hline \multirow{3}{*}{$\begin{array}{c}\text { Type of } \\
\text { vulcanizer }\end{array}$} & \multirow{2}{*}{\multicolumn{2}{|c|}{$\begin{array}{c}\text { Time } \\
\text { Minutes }\end{array}$}} & \multirow{2}{*}{\multicolumn{2}{|c|}{$\begin{array}{c}\text { Temperature } \\
{ }^{\circ} \mathrm{C} \\
\text { Class }\end{array}$}} & \multirow{2}{*}{\multicolumn{2}{|c|}{$\begin{array}{c}\begin{array}{c}\text { Power/fuel } \\
\text { consumed }\end{array} \\
\text { Class }\end{array}$}} & \multirow{2}{*}{$\begin{array}{c}\text { Cost in kWh/ } \\
\text { Gas-ml } \\
\text { Class }\end{array}$} & \multirow{2}{*}{\multicolumn{2}{|c|}{$\begin{array}{c}\begin{array}{c}\text { Rate of energy } \\
\text { consumption }\end{array} \\
\text { Class }\end{array}$}} & \multirow{2}{*}{\multicolumn{2}{|c|}{$\begin{array}{c}\text { Results } \\
\text { Class }\end{array}$}} & \multicolumn{2}{|c|}{ Efficiency (\%) } \\
\hline & & & & & & & & & & & & & \\
\hline & A & B & A & B & A & B & A & A & B & A & B & A & B \\
\hline Electronic & 1 & 2 & \multirow{2}{*}{\multicolumn{2}{|c|}{60}} & $\begin{array}{l}0.005 \\
\mathrm{kw} \cdot \mathrm{h}\end{array}$ & $\begin{array}{l}0.10 \\
\mathrm{kw} \cdot \mathrm{h}\end{array}$ & $\begin{array}{c}\text { Php } \\
15.1441\end{array}$ & $\begin{array}{c}\text { Php } \\
0.0757\end{array}$ & $\begin{array}{l}\text { Php } \\
0.15\end{array}$ & \multirow{2}{*}{\multicolumn{2}{|c|}{$\begin{array}{l}\text { Good } \\
\text { bonding }\end{array}$}} & \multicolumn{2}{|c|}{$85.22 \%$} \\
\hline Conventional & 5 & 10 & & & $20 \mathrm{ml}$ & $30 \mathrm{ml}$ & $\begin{array}{l}\text { Php } \\
0.054\end{array}$ & $\begin{array}{l}\text { Php } \\
1.08\end{array}$ & $\begin{array}{l}\text { Php } \\
1.52\end{array}$ & & & $43.38 \%$ & $78.08 \%$ \\
\hline
\end{tabular}

1.52 and with an efficiency of $78.08 \%$.

Figure 3 and Figure 4 compare the result of the vulcanizing process using the electronic and the conventional vulcanizer at $60^{\circ} \mathrm{C}$ temperature.

Figure 5, shows the graphical data of the conventional (gas fired) vulcanizer that the gum was bonded to the rubber tire at $60^{\circ} \mathrm{C}$ in 5 minutes for a Class A gum, with a fuel consumption of $20 \mathrm{ml}$ valued at Php 1.08 and an efficiency of $43.38 \%$, while Class B gum was bonded at 10 minutes at $60^{\circ} \mathrm{C}$, with a fuel consumption of $30 \mathrm{ml}$ valued at Php 1.52 and with an efficiency of $78.08 \%$.

Therefore, the portable electronic vulcanizer is most efficient than the convention vulcanizer and it is an environment-friendly machine.

Thus, this portable electronic vulcanizing machine saves time and cuts cost in investment and manpower, with 85.22\% efficiency in the performance of vulcanizing.

\section{Summary, Conclusions, Implication and Recommendations}

This section summarizes the facts, the results of experiments and data computed on the study; answers the questions stated on the research work and recommends what can be improved in the research study.

\subsection{Summary}

This study was conducted to make a design and fabrication of a portable electronic vulcanizer. The testing was undertaken at the Bachelor of Technology Department, College of Engineering, University of Eastern Philippines this second semester school year 2005-2006.

The experimental method of research was used. The researcher was responsible for the purchase of the materials needed for the study.

It was found out in this study that portable electronic vulcanizer was effective in vulcanizing interior tires of the automobiles, motorcycles and bicycles. It further showed that the best temperature in which the gum was bonded exactly to the rubber tire was $60^{\circ} \mathrm{C}$ in 1 minute for Class A gum and 2 minutes for Class B gum.

The rate of energy consumed for the portable electronic vulcanizer was Php 0.0757 for Class A gum and Php 0.15 for Class B gum with an efficiency of $85.22 \%$, while the conventional vulcanizer for Class A gum consumed a fuel equivalent to Php 1.08 with an efficiency of $43.38 \%$ while the Class B gum fuel consumption was equivalent to Php 1.52 with an efficiency of $78.08 \%$.

For mass production, this machine cost Php 5700.00 (US \$101.79) only.

\subsection{Conclusions}

Based on the findings of the study, the following conclusions were derived:

1) The design of the portable electronic vulcanizer that weighs $6.30 \mathrm{~kg}$ is made of letter $\mathrm{G}$ body which is made of gauge $20 \mathrm{GI}$ pipe, $3 \mathrm{~cm}$ in diameter with $0.05 \mathrm{~cm}$ thickness flat bar as base. The height of the body is 43 $\mathrm{cm}$; the base is $23.5 \mathrm{~cm}$ length and $10 \mathrm{~cm}$ width; and the panel board with dimension of 27.5 for the height, 22.5 $\mathrm{cm}$ for the width, $8 \mathrm{~cm}$ for the thickness.

2) The material components of the electronic vulcanizer are composed of the timer, temperature gauge/ thermostat, LED, buzzer, relay and 300 watts heating element.

3) The appropriateness of the heating element was demonstrated in the experimentation of this portable 


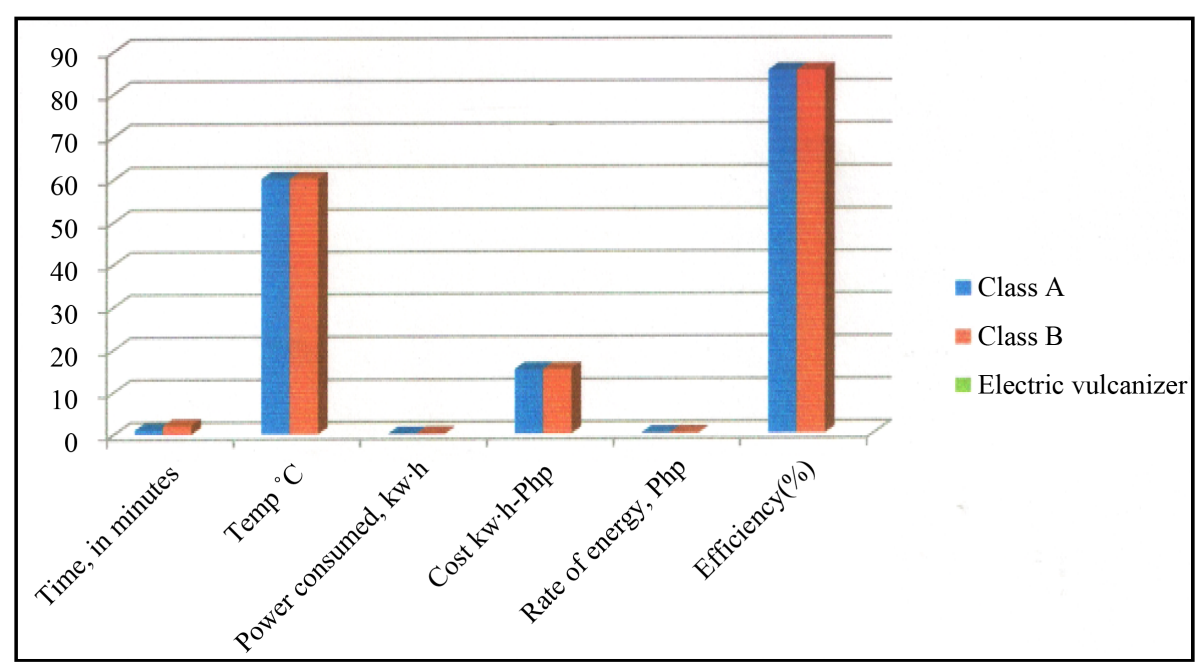

Figure 4. Electronic vulcanizer.

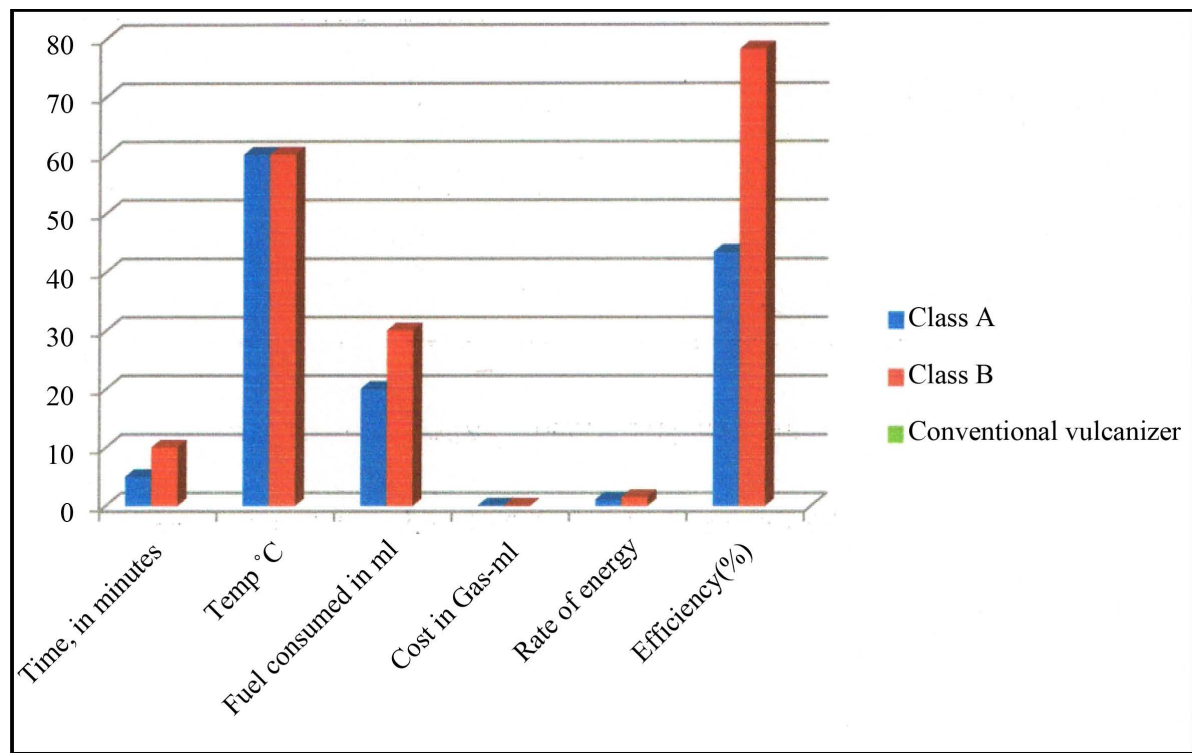

Figure 5. Conventional (gas fired) vulcanizer.

electronic vulcanizer which was a unique flat type heating element material with a 300 wattage output for a low cost power generation consumption.

4) The portable electronic vulcanizer requires $60^{\circ} \mathrm{C}$ temperature in one minute to exactly bond the gum to the rubber tire for Class A vulcanizing gum and 2 minutes at $60^{\circ} \mathrm{C}$ temperature to exactly bond to the rubber tire for Class B vulcanizing gum. The electronic vulcanizer is therefore efficient as it requires only one and two minute (Class A and B vulcanizing gum) to vulcanize as compared to the conventional vulcanizer that needs five minutes to finish the task.

5) In terms of energy consumption rate, the portable electronic vulcanizer is more economical as it consumes an energy equivalent to Php 0.0757 (Class A vulcanizing gum) and Php 0.15 (Class B vulcanizing gum) with an efficiency of $85.22 \%$, as compared to the Php 1.08 (Class A vulcanizing gum) with an efficiency of $43.38 \%$ and Php 1.52 (Class B vulcanizing gum) with an efficiency $78.08 \%$ of the conventional vulcanizer. The efficiency of portable electronic vulcanizer is limited only for the vulcanization of gum to the rubber tires or inner tubes of the automobiles, motorcycle and bicycle or any inflatable rubber materials.

The payback period (PP) of the vulcanizing shop with capitalization of Php 185100.00 (US \$3305.36) including this new electronic vulcanizer is only 3.3356 years operation. 
This study determined the accurate temperature and duration of the vulcanizing process using the electronic vulcanizer which eliminated the problem of gas emission (carbon dioxide) produced by the conventional (gas fired) vulcanizer of about $2.772 \mathrm{~kg}$ of carbon dioxide for 1 liter of diesel fuel and/or $2.331 \mathrm{~kg}$ of carbon dioxide for 1 liter of petrol into the atmosphere.

\subsection{Implication}

The findings of this study have an important implication for future it provides enhancement and improvement of the study. More tires can be vulcanized in a short period of time; there for greater income over time. It is environment-friendly since it does not emit gas as compared to the conventional vulcanizing; and much more is lesser health hazard to the operator.

\subsection{Recommendations}

1) It is recommended that this portable electronic vulcanizer be used in every welding, automotive and machine shop to save time and investment in their operations;

2) $\mathrm{S}$ mall time businesses like vulcanizing shops in the Philippines are encouraged to provide this portable electronic vulcanizing machine so that they can save money and labor in their operation;

3) It is recommended also that this study be innovated thru additional features like automatic shutdown of power supply or may be a remote controlled operation on the power switch.

\section{Acknowledgements}

This research work would not have been realized without the guidance of the Almighty God. Sincerest appreciation and gratitude are likewise extended to the following persons: Dr. Rolando A. Delorino, Vice-President for Research \& Development/Extension and Training, Chair, R\&D In-House Review panel and members; Dr. Pio P. Tuan, R\&D Director and Staff, University of Eastern Philippines, University Town, Catarman, Northern Samar, for their encouragement to present of this research paper. Prof. Villa C. Cinco for editing this manuscript. Atty. Mar. P. De Asis, PhD, President, for giving us full support and enthusiasm of this field of endeavor, and Dr. Zenon Pudlosky, Managing Director WIETE-Melbourne, Australia, for his kind support and allowing the author to present this paper in the $3^{\text {rd }}$ WIETE Annual conference of Engineering and Technology Education on 6-10 February 2012, in Pattaya City, Thailand. Likewise to those who contributed much for the success of this study, particularly my wife, Gigi and children, my friends and colleagues.

\section{References}

[1] US EPA (2014) Green Gas Emission from Typical Passenger Vehicle. http://www.epa.gov/otaq/climate/documents/420f14040.pdf

[2] Ramos, F.V. (1991) Executive Order 318, s. 1991. Making Philippines Industrializing Country (NIC-Hood Philippines), Manila.

[3] Annual Report (1993) Secretary of the Department of Education, Manila.

[4] Encyclopedia Britannica. 15th Edition.

[5] Compton's Encyclopedia. 1995 Edition.

[6] (2008) Tire Vulcanizer. Hirotek Inc., Japan.

[7] (2010) Tire Vulcanizer. Hirata Corporation, Japan.

[8] Ramis, E.Z. (2002) Determinants of Professionalism of Graduate School Students, Faculty and Administrator in State Universities and Colleges in Region VIII. Technological University of the Philippines, Manila. 
Scientific Research Publishing (SCIRP) is one of the largest Open Access journal publishers. It is currently publishing more than 200 open access, online, peer-reviewed journals covering a wide range of academic disciplines. SCIRP serves the worldwide academic communities and contributes to the progress and application of science with its publication.

Other selected journals from SCIRP are listed as below. Submit your manuscript to us via either submit@scirp.org or Online Submission Portal.
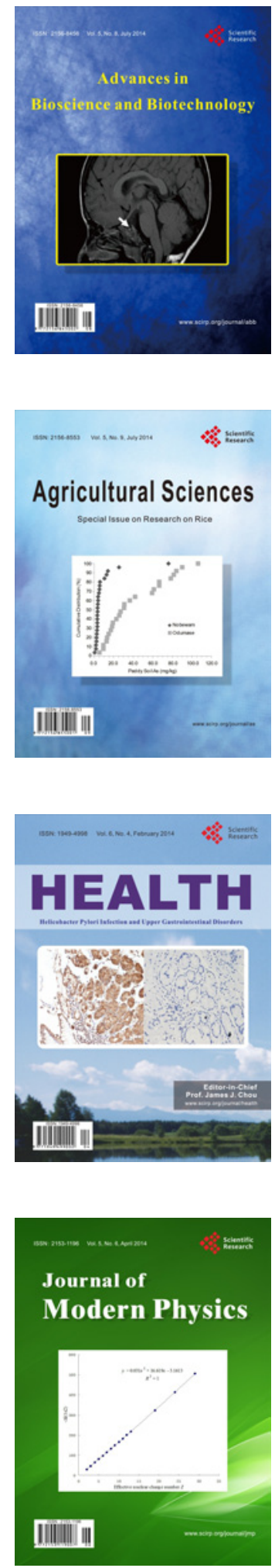
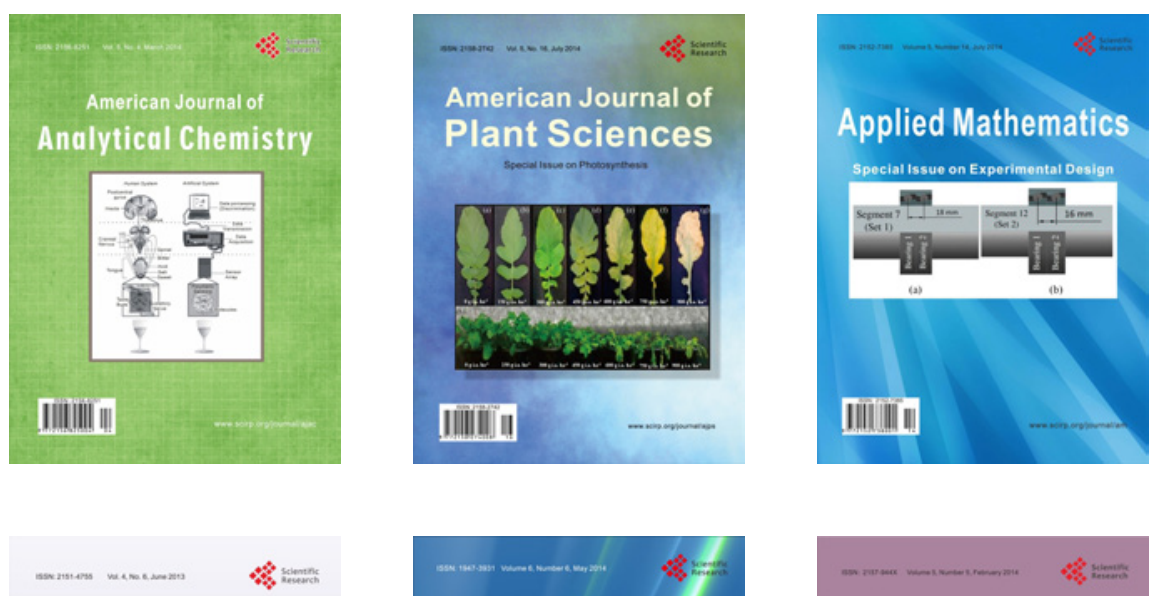

Creative Education
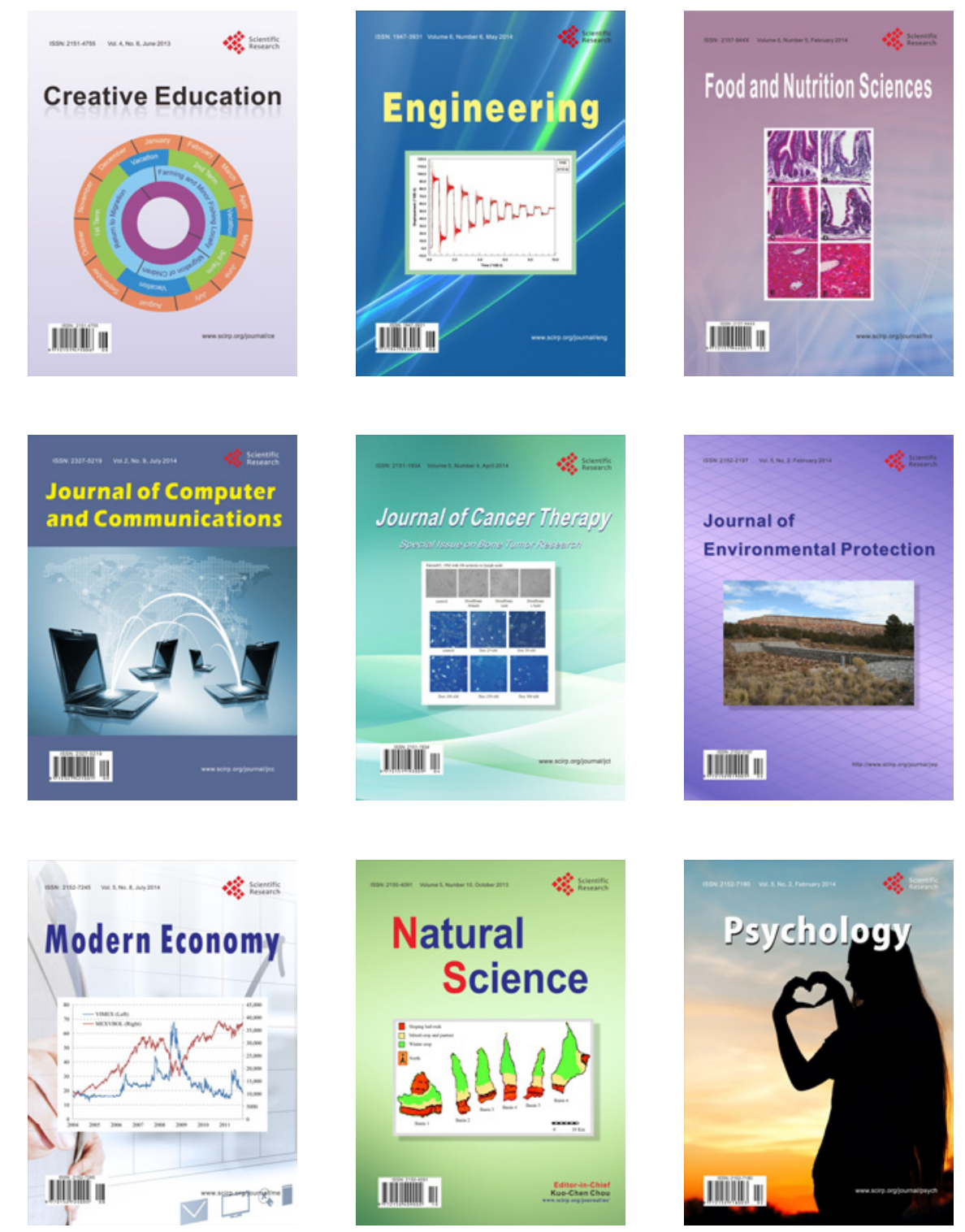